\title{
RANCANG BANGUN ALAT BLIND SPOT AREA PADA KENDARAAN TRUCK TANGKI BERBASIS MIKROKONTROLER ARDUINO UNO
}

\author{
Raditya Galih Kusuma1, Yusuf Muchammad Devara², Tri Handoyo³, \\ Muzayin Arif ${ }^{4}$ \\ Program Studi Teknik Keselamatan Otomotif \\ Politeknik Keselamatan Transportasi Jalan \\ Jalan Semeru No.3 Kota Tegal, Jawa Tengah 52125 \\ E-mail: radityagalih05@gmail.com
}

\begin{abstract}
Abstrak
Semakin pesatnya perkembangan zaman salah satunya perkembangan pada kendaraan truck tangki yaitu blind spot area. Atas dasar latar belakang terserbut selanjutnya muncul permasalahan bagaimana membuat rancang bangun blind spot area pada kendaraan truck tangki agar dapat memberi peringatan kepada pengemudi jika adanya suatu benda/objek pada area blind spot. Penelitian ini bertujuan untuk merancang bangun alat yang akan memberikan informasi dan peringatan terhadap pengemudi adanya objek di area blind spot berbasis mikrokontroler arduino uno. Metode yang digunakan adalah metode uji responsif deteksi alat terhadap objek. Pengujian dilakukan dua kali, yang pertama yaitu pengujian prototipe dan yang kedua pengujian dialakukan pada kendaraan truck tangki secara langsung untuk menguji efektivitas alat baik peringatan berupa suara maupun dari tampilan LCD. Dari pengujian yang telah dilakukan dapat diketahui bahwa rancang bangun blind spot area pada kendaraan truck tangki dapat mendeteksi objek yang berada di area blind spot dengan output dari alat yaitu peringatan bunyi dari buzzer, nyala lampu LED dan LCD yang menampilkan peringatan "HATIHATI JAGA JARAK". Dengan demikian dapat disimpulkan bahwa rancang bangun blind spot area pada kendaraan truck tangki bekerja dengan baik dalam memberikan peringatan kepada pengemudi.
\end{abstract}

Kata kunci: Blind Spot Area, Arduino dan Truck Tangki

\section{PENDAHULUAN}

Pada era globalisasi sekarang ini teknologi berkembang dengan pesat, dimana semuanya bertujuan untuk memudahkan perkerjaan yang ada. Salah satunya adalah teknologi komputer yang memiliki banyak peranan dalam kehidupan sehari-hari. Dengan meningkatnya kebutuhan masyarakat yang menggunakan kendaraan pribadi dalam menyelesaikan berbagai kegitannya. Teknologi semakin dikembangkan untuk menambah faktor keselamatan dan keamaan saat berkendara baik mobil pribadi maupun mobil angkutan/barang (Shihabudin Achmad Muhajir A.K \& Safrina Amini. 2016).

Perkembangan teknologi tidak hanya pada kendaraan pribadi, dalam hal ini kami menyorot pada kendaraan truck tangki. Dengan dimensi kendaraan tangki yang biasanya beroperasi di Indonesia antara lain adalah dengan ukuran panjang keseluruhan kendaraan bermotor lebih dari 9.000 (sembilan ribu) milimeter sampai dengan 12.000 (dua belas ribu) milimeter dan ukuran lebar keseluruhan tidak melebihi 
ukuran landasan dan ukuran lebar keseluruhan tidak melebihi 2.500 (dua ribu lima ratus) milimeter serta tinggi kendaraan tidak lebih dari 4.200 (empat ribu dua ratus) milimeter dan tidak lebih dari 1,7 (satu koma tujuh) kali lebar kendaraannya. Mobil bus maxi yang dirancang dengan Ukuran panjang keseluruhan lebih dari 12.000 (dua belas ribu) milimeter sampai dengan 13.500 (tiga belas ribu lima ratus) millimeter dan ukuran lebar keseluruhan tidak melebihi 2.500 (dua ribu lima ratus) milimeter dan tinggi kendaraan tidak lebih dari 4.200 (empat ribu dua ratus) milimeter dan tidak lebih dari 1,7 (satu koma tujuh) kali lebar kendaraannya (Peraturan Pemerintah Nomor 50 tahun 2012 Tentang Kendaraan).

Keselamatan merupakan suatu keadaan terhindarnya setiap orang dari resiko kecelakaan selama berlalu lintas yang disebabkan oleh manusia, kendaraan, jalan, dan/atau lingkungan (Peraturan Pemerintah Nomor 26 Tahun 2015 Tentang Standar Keselamatan Lalu Lintas dan Angkutan Jalan). Keselamatan dalam berkendara adalah hal yang menjadi perhatian bagi setiap individu. Apalagi dengan dimensi kendaraan yang besar maka pengemudi mempunyai titik buta pada area tertentu pada saat duduk di kursi kemudi. Oleh sebab itu, kendaraan diharapkan memiliki sebuah alat yang dapat membantu pengemudi untuk memberikan peringatan dini, agar terhindar dari kecelakaan. Salah satu alat yang dapat membantu mencegah terjadi kecelakaan adalah rancang bangun blind spot area, yaitu sebuah alat yang membantu pengemudi untuk mendeteksi keberadaan kendaraan/objek lain yang berada disekitar kendaraan dan tidak terlihat oleh pengemudi dalam area jangkauan sensor rancang bangun blind spot area tersebut. Sebuah sensor akan mendeteksi keberadaan benda yang bergerak mendekati area sensor dan mengkomunikasikan dengan perangkat lain yang terhubung dengannya dalam hal ini controller, LCD, maupun buzzer. Adapun tugas sensor mengirimkan sinyal tersebut kepada perangkat yang terhubung dengannya, sehingga pengemudi kendaraan dapat mengantisipasi keberadaan objek lain yang ada di sekitarnya. (Poltak Leonardo, Dede Sagita, \& Wiedjaja. 2011)

Teknologi rancang bangun blind spot area kebanyakan saat ini hanya terdapat pada kendaraan tertentu saja yang sudah terintegrasi dengan kendaraan tersebut. Jika ingin memiliki dan menggunakannya, pemilik kendaraan harus mengeluarkan biaya tambahan. Terlebih lagi biasanya teknologi rancang bangun blind spot area relatif mahal, dengan segi fitur yang lumayan lengkap. Di sisi lain banyak pengguna teknologi tersebut membutuhkan fitur rancang bangun blind spot area yang sederhana saja. Oleh karena itu rancang bangun blind spot area berbasis mikrokontroler Arduino Uno merupakan teknologi yang cocok karena memiliki fitur sederhana. Rancang bangun blind spot area ini bekerja memberikan peringatan dini kepada pengemudi melalui LCD, LED dan buzzer yang terhubung dengan sensor, dan mikrokontroller yang ada. Pembuatan aplikkasi rancang bangun blind spot area ini bertujuan untuk membantu mempelajari teknologi rancang bangun blind spot area secara umum, cara kerja, prinsip kerja, dan perkembangan yang ada pada saat ini, sehingga menambah pengetahuan bagi yang membaca dan membahami arti pentingnya sebuah alat rancang bangun blind spotarea, dalam hal menjaga dan mencegah adanya kecelakaan di jalan ketika seorang pengemudi mengendarai kendaraannya. Dengan metode komunikasi serial menggunakan beberapa pendukung yaitu sensor Ultrasonic SRF04 sebagai sensor pendeteksi keberadaan benda atau mobil, sensor inframerah sebagai pengirim data dari sensor Ultrasonic SRF04, mikrokontroler Arduino Uno sebagai pengolah data, LED, buzzer dan monitor sebagai penunjuk objek benda yang berada 
di blind spot arae, untuk memberikan informasi dan peringatan kepada pengemudi agar tidak terjadi kecelakaan akibat blind spot area.

\section{METODE PENELITIAN}

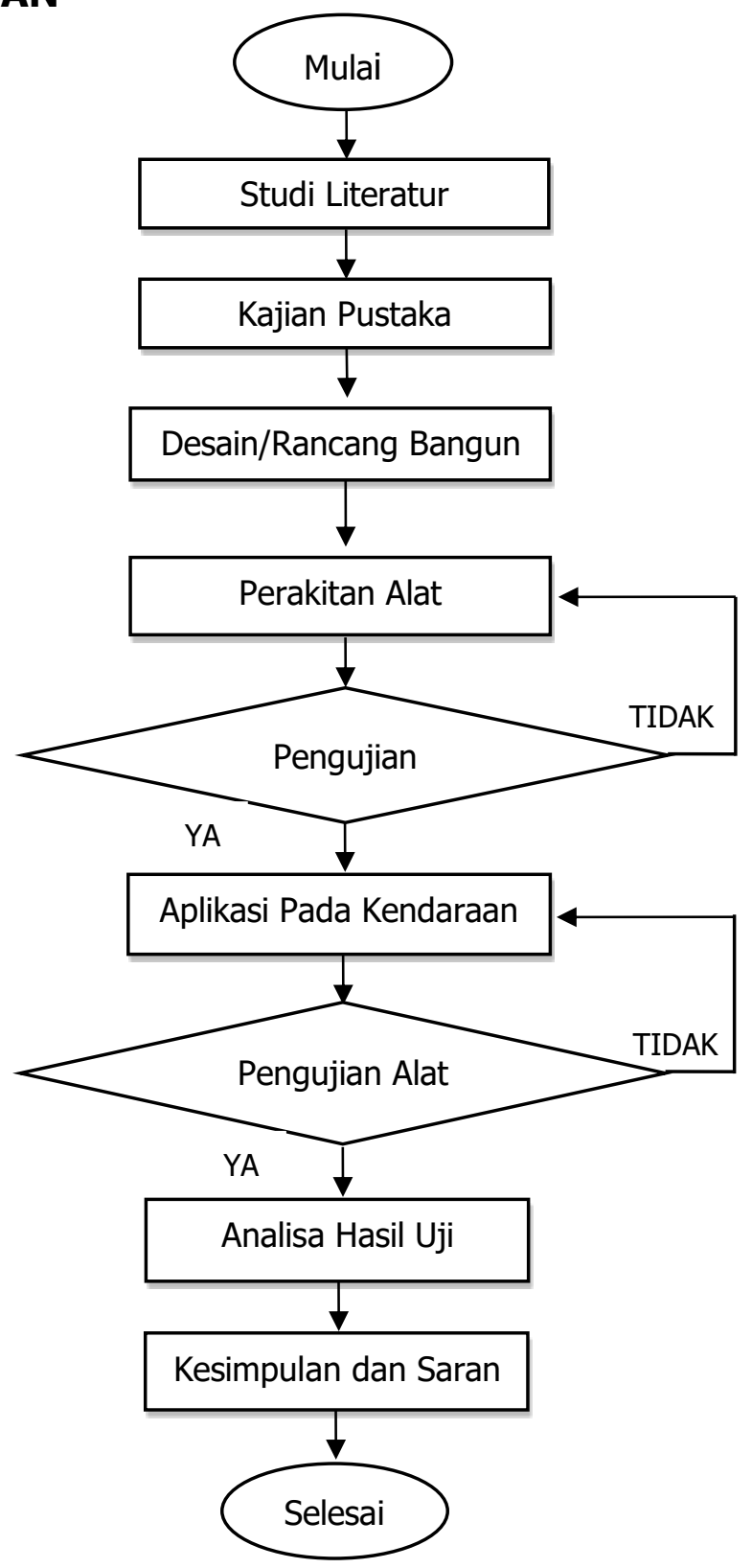

Gambar 1. Diagram Alur Penelitian

\section{HASIL DAN PEMBAHASAN}

\section{Perakitan Sensor}

Pemasangan sensor dilaksanakan dengan memperhatikan dua tahap berikut:

a. Menentukan Kaki Sensor

Setiap Kaki sensor terdapat beberapa port yang mempunyai input berbeda, perlu diperhatikan agar pemasangan tidak terbalik.

b. Memastikan Pemasangan kaki sensor tepat pada port sensor

Setelah kaki sensor dan port telah diketahui dengan pasti, maka pemasangan dapat dilaksanakan dengan tepat. 


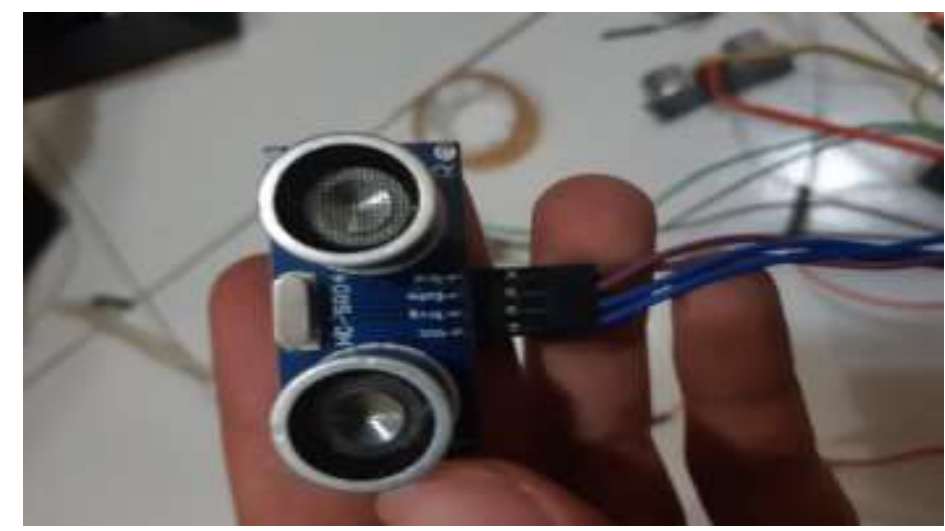

Gambar 2. Perakitan Sensor

2. Perakitan Buzzer

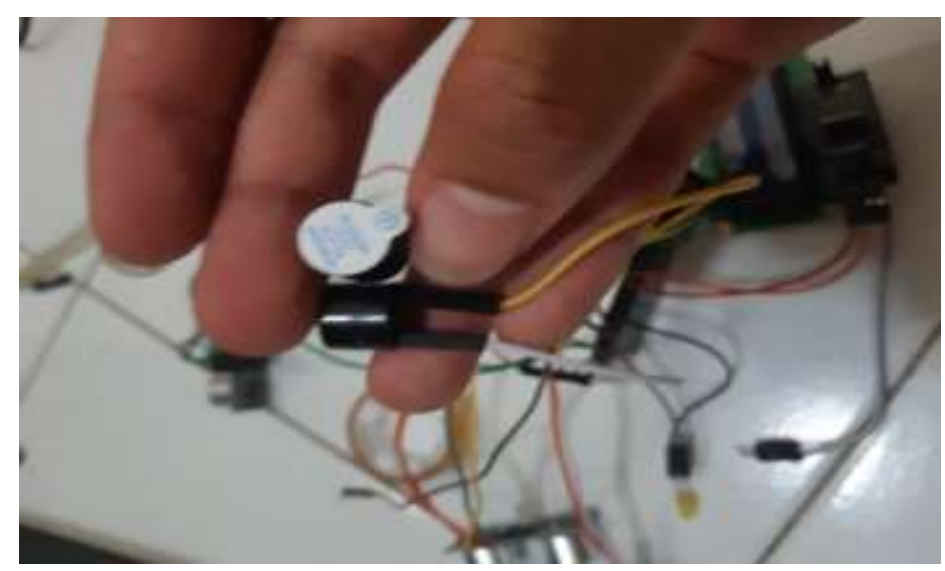

Gambar 3. Perakitan Buzzer

a. Menentukan Kaki pada buzzer.

b. Merangkai buzzer dengan menggunakan soket kabel penghubung ke port Arduino Uno.

1. Kaki positif ke port no 5 Arduino Uno

2. Kaki negatif ke port GND Arduino Uno

3. Perakitan LED

a. Menentukan Kaki pada LED.

b. Merangkai LED dengan menggunakan soket kabel penghubung ke port Arduino Uno.

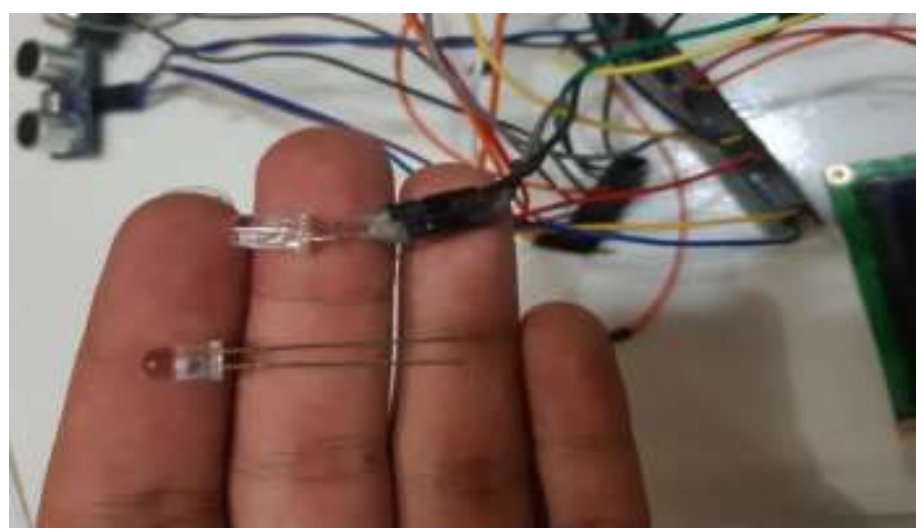

Gambar 4. Perakitan LED 
4. Perakitan LCD

a. Menentukan Kaki pada LCD.

b. Merangkai LCD dengan menggunakan soket kabel penghubung ke port Arduino Uno.

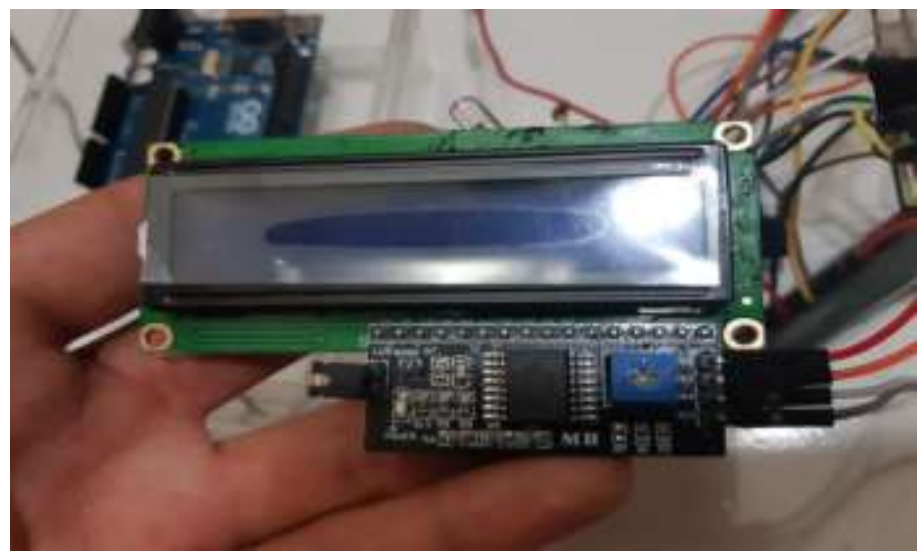

Gambar 5. Perakitan LCD

5. Pemasangan Alat Pada Box

a. Menentukan posisi setiap alat pada box agar tertata rapi.

b. Mebuat lubang pada box untuk keperluan alat yang berada di luar box.

c. Perakitan alat pada box.

6. Pemrograman

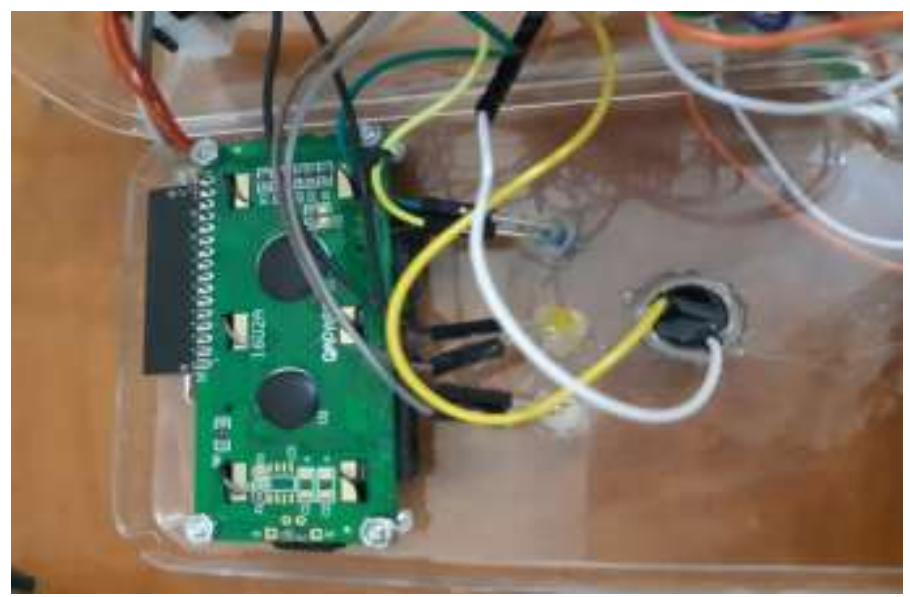

Gambar 6. Pemasangan Alat Pada Box

Pada tahap ini membuat bahasa pemprograman menggunakan Arduino IDE. Membuat bahasa program memerlukan ketelitian khusus karena setiap langkah dari program adalah otak dari kinerja sensor. Dengan tampilan arduino IDE yang sudah terinstal pada komputer dengan bentuk exe. Berikut menu tampilan arduino IDE untuk melaksanakan pemograman yang meliputi:

a. File berfungsi untuk membuat scetch baru, menyimpan sketch, membuka preferences, pilihan keluar dari program dan lainnya

b. Edit berfungsi untuk copy, paste, cut, Select All untuk menyeleksi semua kode yang sudah ditulis dan lainnya.

c. Veryfy berfungsi untuk memverifikasi skecth yang telah di buat 
d. Upload digunakan untuk mengunggah scetch yang telah dibuat dan dikompilasi ke Arduino.

e. Include library berfungsi untuk memilih, mengatur, memperbarui, mengunduh library arduino secara offline yang berupa file dengan eksistensi zip yang akan digunakan.

f. Tools terdapat menu yang digunakan untuk memeilih jenis board Arduino dan pilihan Port Com, sedangkan menu programmer digunakan untuk memilih programmer yang digunakan untuk mengunggah skecth yang telah dibuat ke Arduino.

g. Help digunakan untuk mencari informasi dan langkah-langkah terkait Arduino.

h. Serial Monitor digunakan untuk memilih data-data berupa karakter, angka maupun text yang dikirimkan dari Arduino ke komputer.

\section{PENUTUP}

\section{Simpulan}

1. Rancang bangun blind spot area pada kendaraan truck tangki berbasis mikrokontroler arduino uno dapat terealisasi menjadi sebuah alat yang dapat diaplikasikan dan disimulasikan pada kendaraan truck tangki.

2. Kinerja rancang bangun blind spot area pada kendaraan truck tangki berbasis mikrokontroler arduino uno dapat dieroleh dari pendeteksi objek dari sensor ultrasonik, kemudian buzzer akan mengeluarkan bunyi, LED akan menyala sesuai dengan sensor ultrasonik mana yang mendeteksi objek sedangkan LCD monitor akan menampilkan "HATI-HATI JAGA JARAK" sebagai peringatan terhadap pengemudi. Namun dalam hal lainnya kapasitas port arduino uno sangatlah sedikit sehingga ada satu sensor ultrasonik yang tidak ada tanda peringatan dari nyala LED dan jumlah sensor ultrasonik hanya empat yang dirasa sangat sedikit untuk diterapkan pada kendaraan truck tangki yang ukurannya sangat besar. Selanjutnya karena ukurun kabel yang disediakan peneliti kurang memadai sehiangga box rangkaian tidak bisa diletakan di dashboard kendaraan dan oleh karena itu juga ada satu sensor yang tidak terpasang yaitu bagian belakang.

\section{Saran}

Pada penelitian selanjutnya diharapkan bisa diterapkan dengan baik pada kendaraan truck tangki guna memberikan peringatan dini kepada pengemudi. Penelitian selanjutnya arduino uno dapat diganti menjadi arduino mega yang kapasitas portnya lebih banyak agar dapat menambahkan sensor ultrasonik maupun LED untuk pengembangan alat agar lebih komplit.

\section{DAFTAR PUSTAKA}

Ladjamudin, Al-bahra. (2005). Analisis dan Desain Sistem Informasi. Yogyakarta : Graha Ilmu

Leonardo, Poltak, Dede Sagita, \& Wiedjaja. (2011). Vehicle Blind Spot Detection System Berbasiskan ATMEGA 168.

Ma'arij, Yuzan Aji. (2015). Rancang Bangun Alat Deteksi Overheating (Panas Berlebihan) Pada Mesin Berbasis Microcontroller Arduino Uno.

Mc Leod, Raymond. (2002). Sistem Informasi Manajemen. Jakarta : Prenhallindo 
Mujahir, Shihabudin Achmad A.K, \& Safrina Amini. (2016). Sistem Monitoring Tempat Parkir Dengan Sensor Ultrasonik Berbasis Arduino Uno Pada Cibinong City Mall.

Mukminin, Miftahul \& Agus Budi Santosa. (2016). Pengaruh Media Pembelajaran Software Proteus Pada Mata Pelajaran Penerapan Rangkaian Elektronika Terhadap Hasil Belajar Siswa Kelas XI Teknik Audio Video di SMK Negeri 3 Surabaya.

Pressman, Roger S. (2002). Rekayasa Perangkat Lunak Buku 1 (Terjemahan) Yogyakarta : Andi 